THE INTERNATIONAL

REVIEW OF RESEARCH IN

OPEN AND DISTANCE LEARNING

\title{
Increased Technology Provision and Learning: Giving More for Nothing?
}

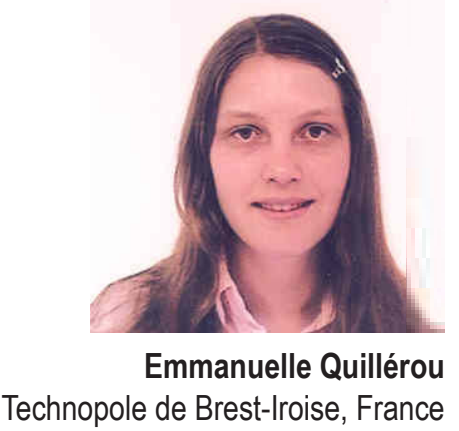

\section{Abstract}

The development of new communication technologies has led to a push for greater technology use for teaching and learning. This is most true for distance learning education, which relies heavily on new technologies. Distance learning students, however, seem to have very limited time available for studying and learning because of work and/or family commitments. This paper focuses on the actual use by distance learning students of different teaching and learning resources and their associated teaching technologies (learning tools). The organisation of one module has been conceptualised as a toolbox, encompassing all the learning tools provided to students. This toolbox also explicitly includes an embedded priority system for the examination of available learning resources, conceptualised as a traffic-light toolbox in this paper. Results from a survey on the resources actually used by students show that students are indeed time-constrained. Students consequently follow the priority system embedded into the module and do not use non-examinable resources much. This paper concludes that students' specific needs or situations need to be considered for the design of an effective learning toolbox, as opposed to just providing a bundle of learning tools that may be effective on their own.

Keywords: Distance learning; technology; priorities; time-constraint; module organisation

\section{The Push for Greater Technology Use and Time for Learning}

Communication technologies are now part of most aspects of our lives, and the educational sector is no exception. This is true for distance learning (off-campus) and also increasingly for campus-based education with a combination of face-to-face and off-campus teaching. This greater use of communication technologies in education is associated with the current rationale underlying university curriculum building for both on- and off-campus provision 
(i.e., blended learning.) Blended learning, according to the literature, enhances learning most effectively (Garrison \& Kanuka, 2004) and can be defined as "[the design and delivery of] the right content in the right format using the right mix of media" (Debande \& Ottersten, 2004, p. 34, adapted by Boitshwarelo, 2009, p. 2, emphasis added).

These "new" communication technologies were first used to facilitate educational provision through material distribution and interaction. These technologies later led to the design of specific technology-based educational tools to enhance teaching and (blended) learning. These technology-based educational tools are now fully embedded in the university curriculum as media for educational provision. These tools are customised to specific contexts and issues faced when enhancing teaching and learning. Most studies on the use of technologies for learning and teaching detailed in the literature so far have focused on some of the following issues:

- how to promote online interaction and the building of learning communities, seen as a necessary condition for effective learning (e.g., Beldarrain, 2006; Brindley, Walti, \& Blaschke, 2009);

- the effectiveness of web-based compared to face-to-face learning and teaching (e.g., Cheaney \& Ingebritsen, 2005; Brown \& Green, 2009);

- $\quad$ assessing the effectiveness of any given technological tool to induce learning (e.g., Kodama, 2001);

- the paradigm shifts induced by technological and distance learning developments; as the technology develops, it induces revisions in distance learning design and provision (e.g., Beldarrain, 2006); and

- the paradigm shifts toward student-centred learning and teaching in relation to student demands and toward blended learning (e.g., Beaudoin, 1990; Calder, 2000).

Because of their common off-campus nature, campus-based education with some off-campus teaching and distance learning education face similar issues. Off-campus educational provision is complemented, however, by on-campus face-to-face interactions, which is not the case in distance learning. Consequently, technology-based educational tools used in campus-based education with some off-campus teaching and in distance learning education are similar to a certain extent but are not necessarily the same.

Distance learning can be simply defined as (higher) education that is not delivered on a face-to-face basis, (i.e., education that is necessarily fully provided off-campus) (Calder, 2000). It is interactive, with email exchanges and discussions mostly on an asynchronous basis (Cheaney \& Ingebritsen, 2005). Distance learning also requires independent study of the material compared to an equivalent face-to-face setting (Bray, Kumiko, \& Dlugosh, 2008). This form of education has been promoted as being more inclusive through widening participation (Calder, 2000). Distance learning attracts students who have very heterogeneous learning styles and who are different from those involved in campus-based edu- 
cation (Berenson, Boyles, \& Weaver, 2008). Distance learning students are usually found to be self-regulated (e.g., Lynch \& Dembo, 2004; Artino, 2009) and self-directed in their learning (Bose, 2003). One of the main weaknesses of distance learning identified in the literature, however, is that these students are not very well known by their tutor and the people designing the course (as reported by Blakelock \& Smith, 2006).

Also, paradoxically, distance learning can be both time-saving and more time-consuming, time-saving because saving time on travel allows greater flexibility in terms of the study time and place (Bose, 2003; SOAS, 2009; Arendt \& Shelton, 2009) and more time-consuming because it takes longer to study and learn the material to be covered (Brown \& Green, 2009). The theoretical literature and universities overall seem to be pushing for greater adoption of technological advances and tools. One of the dangers is that this push-so far unquestioned in the literature-could lead to an increase in the overall load of material to be covered and could render the identification of important information more difficult and time-consuming. Increased technology provision in distance learning could thus undermine the students' learning time-effectiveness and efficiency. More specifically, the actual relevance of this push for greater technology provision can be questioned for distance learning students, who are typically subject to a very strong time constraint and high workload (Blakelock \& Smith, 2006). This time constraint might impact students' actual use of the technological teaching and learning tools provided, also depending on other factors, such as whether the material is examinable. Students' actual use of these tools will determine their effectiveness for learning and teaching: If not used, even the best learning tool cannot be effective for learning and teaching.

Three components for effective learning based on underlying modes of interaction have been identified in the literature: (i) technological tools as the basis for the type of educational content supply, (ii) student-centred delivery (i.e., in relation to demand), and (iii) teacher-centred teaching (i.e., in relation to supply) (Anderson \& Garrison, 1998, cited by Anderson, 2003; Calder, 2000; Bray et al., 2008). In this framework, the current push for increased technology provision would seem based on supply only (i and iii), ignoring students' needs and demands (ii).

Hence the question of whether the technological tools provided are actually used by students, and if yes, which of these tools are used. This paper aims to investigate this question based on a survey of distance learning students. It thus focuses on the actual use by distance learning students of different teaching and learning tools, specifically the use of nonexaminable resources under the strong time constraint imposed by each student's personal situation (because of family responsibilities and/or work).

Because of the nature of the case study, each of the technological tools considered is associated with specific types of teaching and learning resources. This paper does not aim to study the impact of a change in the technology to enhance learning for a specific resource, but rather considers a technology and a learning resource as a bundle, with the chosen technology assumed to be the most appropriate for a given learning resource under both time and technological constraints. This paper does not study the teaching pedagogies behind 
the course design and technological tools or their actual effectiveness or efficiency. This approach simply emphasises that the best-designed technology-based tools need to actually be used by students to have a chance of being efficient for teaching and learning. This study is about checking that the supply of teaching and learning tools facilitated by specific technologies matches time-constrained students' demands. The study is particularly relevant in relation to better targeting the type of learning resources and associated technologies used by students.

This study also highlights the importance of the (distance learning) module design for the effective use of resources potentially associated with effective learning (Calder, 2000; Bray et al., 2008). It contributes to the current academic literature by describing a module organisation adapted to time-constrained students. This relatively common module organisation has not yet been described as a traffic-light toolbox (i.e., a toolbox of learning resources with an embedded priority system for examination).

\section{An Example of Distance Learning Provision}

The distance learning programme considered as an example in this paper is part of the University of London's Distance Learning Programme. Students are doing masters-level courses, some of them while working full time (in international organisations, consultancy firms, or government agencies). Because of the challenging nature of this context, this programme tends to attract bright students who are scattered around the world and who are subject to strong time constraints. Consequently, they also tend to be very motivated by their chosen topic of study, regardless of whether resources are examinable.

The academic year runs from February to October. As part of their programme of study, students have to complete some core modules and some elective modules. For each selected module, students receive a study guide, course textbooks, and key readings and have access to a virtual learning environment where they can interact together or with the designated module tutor. Each module study guide is divided into 10 units detailing the course core concepts in a written format. Each of these units is explicitly associated with specific key readings, including textbook sections and further readings. The key readings are compulsory (i.e., examinable) and further readings are optional. Specific links to the key readings and textbook sections were originally embedded within the text of each study guide unit but have been moved to the start of the unit, independent from the unit text. This was a practical measure, taken to facilitate changes to the individual components of the module material (i.e., study guide, key readings, textbook).

The evolution of the learning environment and the courses' written material seems to have been subject to two antagonistic principles:

- more independence between the core examinable materials (study guide units, textbook, and key readings) as a consequence of a practical approach to facilitate course revisions; and 
- a greater inclusion of (extra) resources under the same platform (while remaining independent from one another).

The integration of the material-by linking all course resources together-now falls increasingly on students and tutors. Under a very strong time constraint and with a relatively demanding examinable core part, effectively linking the material together could thus become more difficult. These two mechanisms could also increase the time constraint placed on students by inducing a trade-off between the time spent learning or reflecting on the course material and the time spent identifying the important resources, as well as the time needed to link them together. These design problems for effective learning have been discussed in the literature (for more details, see Bouras et al., 2000; Anderson, 2003; Pituch \& Lee, 2006; Kirkwood \& Price, 2006).

Students can practice their exam skills through two tutor-marked assignments submitted on a voluntary basis. There is no formal deadline for tutor-marked assignment submission, only a suggested deadline in the module's study calendar. The tutor provides feedback within 10 to 15 days of submission. The general guidelines provided to tutors also recommend making information and discussions as available as possible to every student in order to achieve as widespread a diffusion of information as possible. Tutors send monthly e-digests to students, summarising the main points from the units, the main questions and answers, and the main extra resources posted in the online discussion. In practice, e-digests allow better learning resource access for those with a limited Internet connection (e.g., students in Africa) and psychologically help students to feel more connected to the group, as well as supported by their tutor.

The virtual learning environment is available through a Web interface for each module and includes by default a discussion forum section, the course study guide (each unit separately uploaded as a PDF file), a folder with all module e-digests sent out so far, a section where students can upload their tutor-marked assignments, and a section with exam papers from the previous two years. Module discussion forums were shared between several modules until 2009, and afterward became module-specific with an academic focus. In all years, students had access to separate complementary transversal discussion areas (i.e., discussion areas that are not dedicated to one or a group of pre-identified modules). Since February of 2009, tutors have been able to customise the virtual learning environment structure by creating folders and embedding extra resources such as wikis, videos, podcasts, RSS feeds, and Web sites (rather than posting links in the discussion area). The virtual learning environment features a built-in electronic module calendar with a link included in the course outline to increase its ease of access. This calendar is not provided by default but can be customised by tutors. This feature can potentially help students keep track of and pace their study, compared to using the paper-based version of the calendar. Students can also contact their tutor directly by email. 


\section{Conceptual Framework: The Traffic-Light Toolbox}

From a tutor's perspective, the features of the virtual learning environment that allow embedding extra resources (e.g., Web sites, videos, podcasts, RSS feeds, wikis) provided some new opportunities. First, this new virtual learning environment makes it easier to check if these resources have been posted already, avoiding double posting. Second, these resources can be transferred to the following year's module material, which saves time and effort for the tutor across the years. Third, all these resources are relatively independent: It is easy to edit the list of extra resources over the study year and between study years. As it is quite time-consuming to upload all these extra resources in the first place, this is only worth doing as an investment in future gains in the tutor's time-effectiveness and only if students use the resources.

Distance learning students enrolled in this programme are usually very time-constrained, which effectively shortens the time they have to spend on the virtual learning environment, whether it be to read materials or to download and upload resources. This is particularly true for students who have a limited Internet connection, either because of the technical infrastructure to which they have access or because of personal reasons. Because of this time constraint, making information easier for students to find should intuitively make the time spent online more effective for learning purposes. The online module organisation could potentially be very important for students to make the most of the study material provided. This has been stressed in the context of integrating different technologies for teaching provision (Bouras et al., 2000). The standard module outline on the virtual learning environment has consequently not changed much in order to leave it comparable to the other modules read by students (i.e., with common organisational features between modules). This could make it easier for students to find information more effectively once they are familiar with the online virtual learning environment.

The following conceptual framework was developed based on the actual distance learning course design but could easily be adapted to different resources or module organisations. This conceptual framework has been represented schematically in Figure 1. Simply phrased, the module is seen in this paper as a toolbox, represented as the outer green ellipse, grouping different learning and teaching tools (rectangles and smaller ellipses). These tools include the individual course components, each associated with a corresponding teaching technology (PDF files, emails, discussion areas, wikis, RSS feeds, Web sites, videos). The tools considered here are only those provided to students by the programme. 


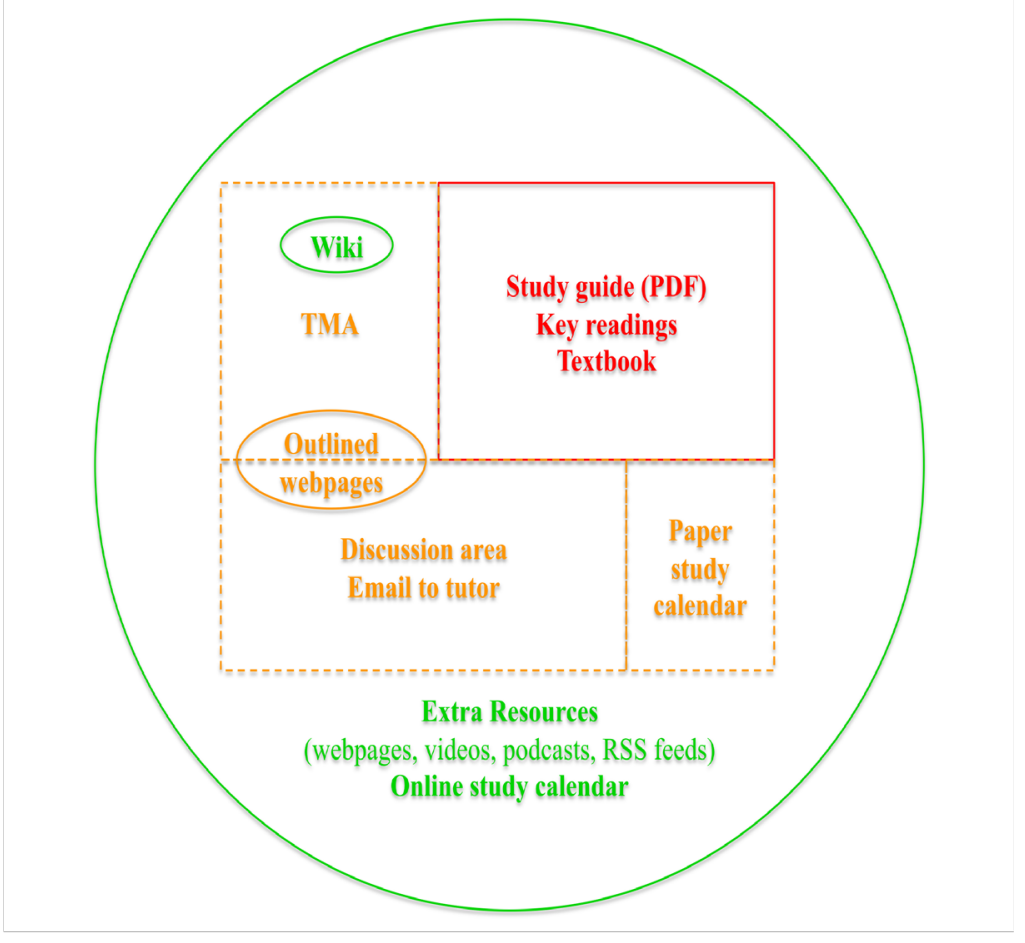

Figure 1. Teaching tools supplied to students and toolbox (red - examinable resources; orange -optional resources but strongly recommended; green - purely optional resources).

Within the general toolbox, the standard core toolbox is represented in red, showing the compulsory and examinable parts of the material. The resources represented in orange are provided to all students by default for all modules, and their use is strongly recommended. These resources are not examined as tutor-marked assignments are assessed but do not count toward the final official module assessment. The resources represented in green rely on a customisation of the virtual learning environment by each tutor. These resources are posted for students to use on a purely voluntary basis.

This traffic-light hierarchy of available resources, or traffic-light toolbox, is thus based on resource examinability, with a corresponding emphasis placed by tutors. This hierarchy has been adopted by the University of London External Programme to help students manage the information load effectively by prioritising what needs to be studied and learned. It is, however, the first time that this module organisation has been formally conceptualised as a traffic-light toolbox system.

So far, most students detail the module's theoretical knowledge well but fail to step back and use real-life examples to discuss the validity of the theory in their tutor-marked assignments. This occurs despite a requirement to do so, explicit encouragement, and the uploading of extra resources. Evidence from past tutor-marked assignments would suggest that the extra (green) resources remain underused to this point, thereby not leading to "critical learning." This particular analysis is based on the above framework. This study focuses on 
the use students make of the extra resources, represented in green in Figure 1. The use of these extra (green) resources might be limited for two reasons: They are non-examinable and are therefore not considered important by students, or students do not have enough time to look at them.

In such a context, is adding new resources really efficient in terms of learning? Several questions arise from the new online and course formats and form the basis for the questionnaire distributed to students:

1. Do students perceive these extra resources as making their learning more effective?

2. Since only the course file, key readings, and textbook content are examinable, do students actually use the extra resources (beyond the "wow factor")?

3. Does embedding the additional resources in the online learning environment increase their use for effective learning compared to previous years (web links included in the discussion area exclusively)?

4. Are students focusing on resources specifically outlined in the discussion area (still posted as threads) or do they also look at the more general "embedded" additional resources?

5. Does the material require more explicit built-in linkages (cement) between the different building blocks (course file, key readings, textbook, extra resources, etc.) or do students like having more initiative?

6. Does the study calendar posted online help students keep up with the course content better than in previous years?

These questions should help identify the main reasons behind the (limited) use of extra (green) resources.

\section{Student Survey Design and Results}

A survey was designed to answer the above six questions as well as to identify some of the students' characteristics. The student population considered was tutored by the author for three consecutive years (between 2007 and 2009) across two different modules. The two modules are part of two separate degree programmes, potentially attracting different students. These programmes, however, are not completely independent, and students may have taken only one or both modules. This survey relied on voluntary answers from students, with a potential sampling bias arising from the spontaneous answering. The survey questions were designed to be relatively general about the virtual learning environment and module used, with control questions on which and when modules are taken and students' characteristics. Because this survey exclusively targets distance learning students, it focuses only on the online resources provided. This survey could be adapted to assess a 
campus-based programme, with the inclusion of lectures and seminars as supplementary teaching tools.

Two hundred and fifty-one students were contacted by email in early August of 2009 and asked to fill in an online semi-structured questionnaire (Bristol Online Survey). Following technical problems, a Word version of the document was also made available later that month, offering students the choice of either filling in the online questionnaire or the Word document. Twenty-five students answered by filling in the online form and 21 filled in the Word document, amounting to 46 answers in total (response rate of 18.33\%). Students had similar answers, so the following results sum up the most frequent answers provided to the survey questions. This analysis helps identify the main patterns emerging from the survey. Students did not always answer all questions, hence there are some discrepancies in the total student numbers in the results described below.

Twenty males and 26 females answered the survey, making a relatively balanced sample gender-wise. Twenty-one students are Europeans or based in Europe (7 students in the United Kingdom and 14 in the rest of Europe), 11 are based in Africa, 5 in America ( 3 in North America), and 3 in Asia. The students ages' ranged from 35-44 (20 students), 25-34 (17 students), 45-54 (6 students), and 55+ (one student). Most of them have family and child-care responsibilities and work outside of normal office hours (respectively, 32, 26, and 35 of the 46 students). Students do take a variety of different modules but all took at least one of the modules tutored by the author.

Students reported using the online learning environment an average of 6.5 hours a month but with great variability (Figure 2). This time presumably does not include the reading of the core examinable material of the course. Forty-eight percent of students log in very regularly, that is once every 1-2 weeks (Figure 3), and 59\% of students log in more frequently as the study year progresses (Figure 4). Students using extra resources reported doing so on an irregular basis, approximately every 3 weeks on average (Figure 5). 


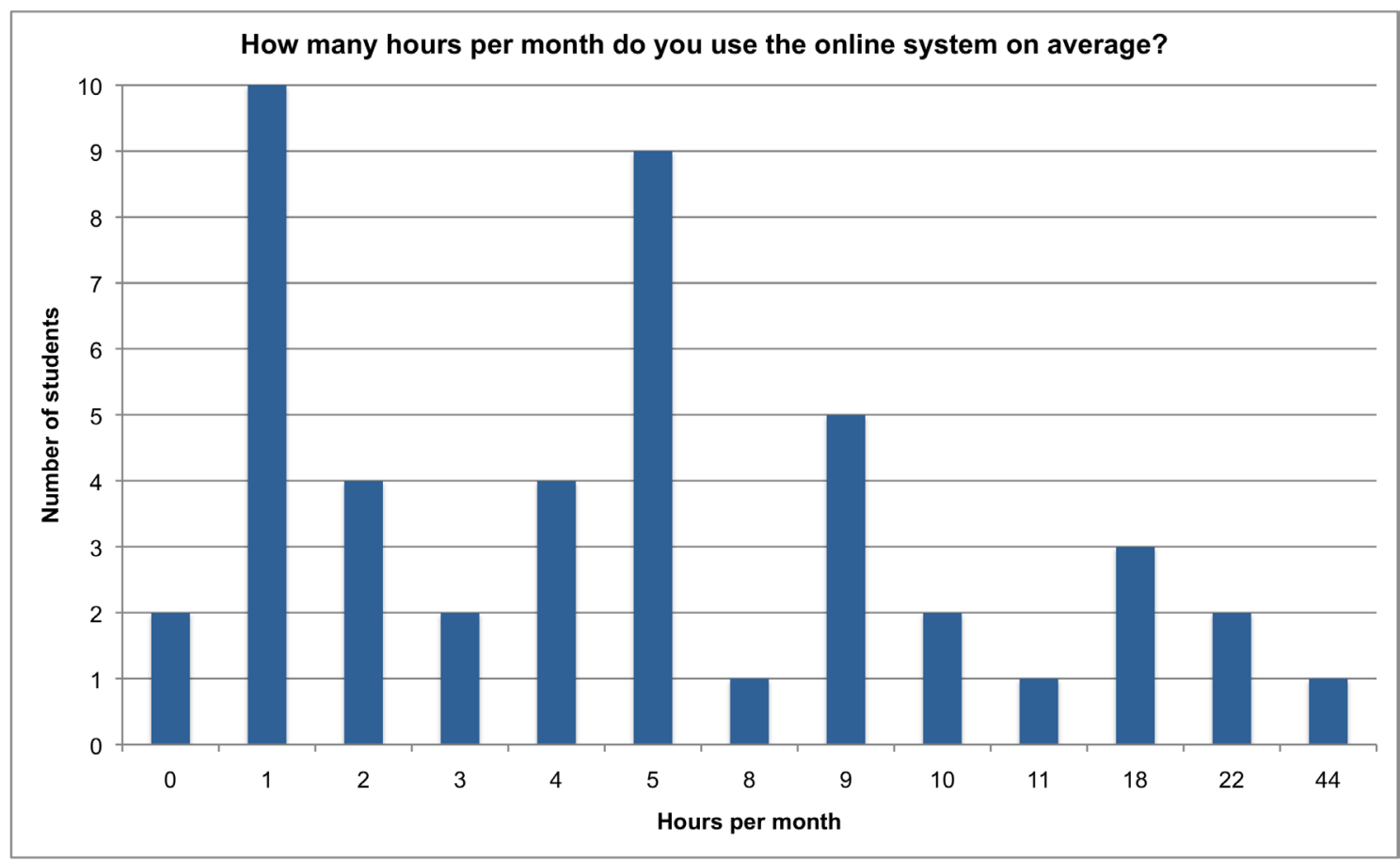

Figure 2. Self-reported time spent by students on the online learning environment.

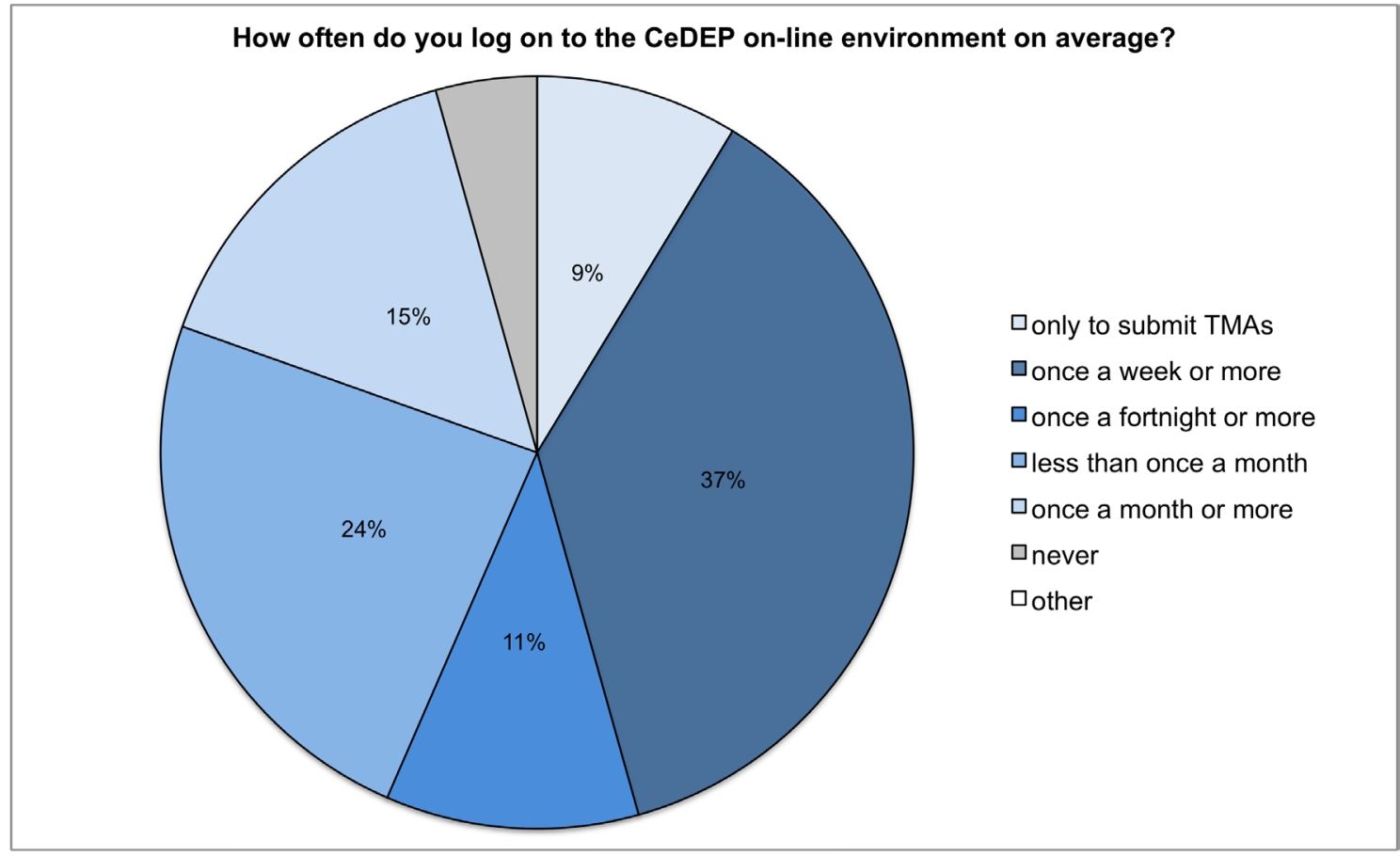

Figure 3. Student use of the online learning environment. 


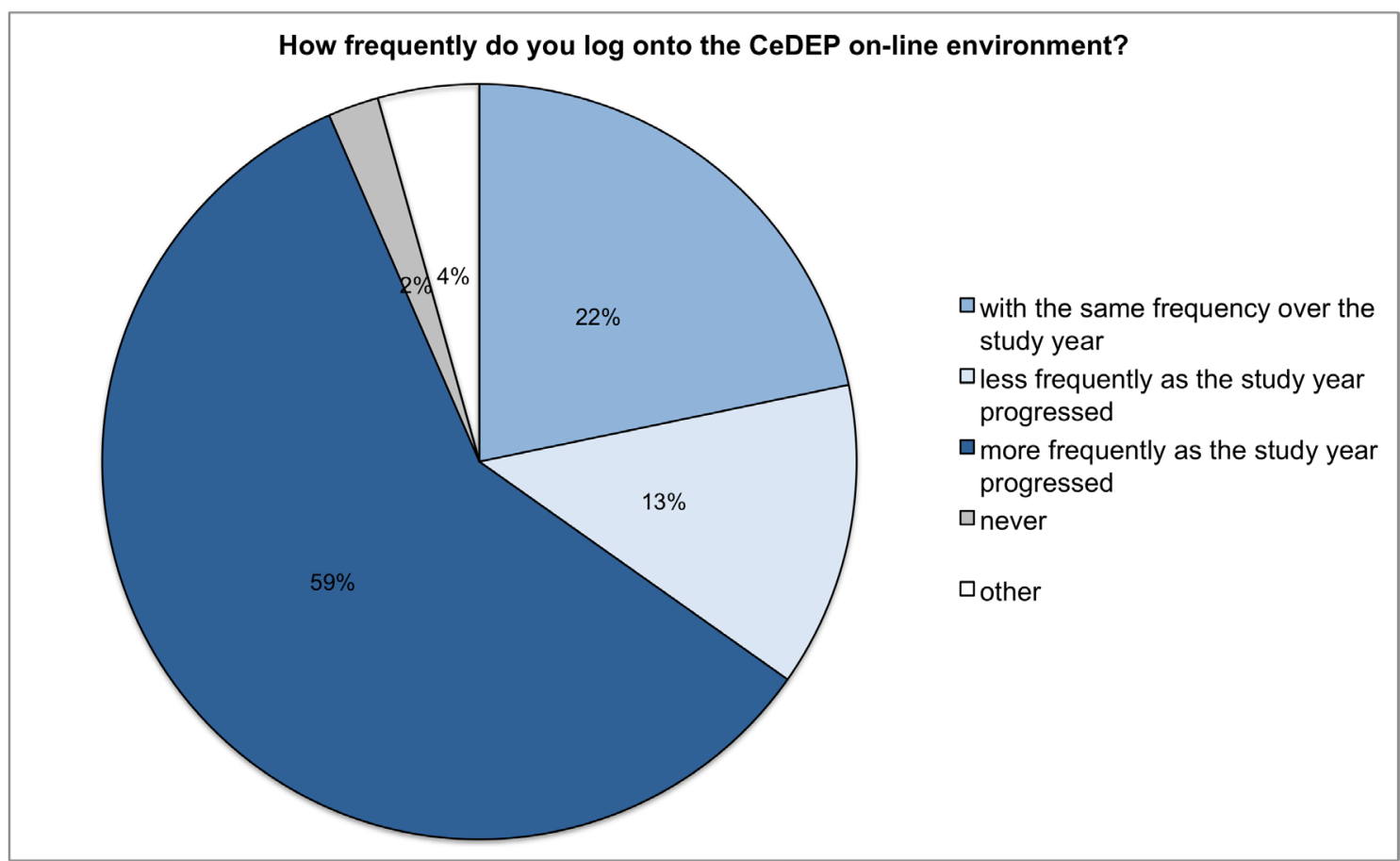

Figure 4. Frequency of student use of the online learning environment over the course of the study year.

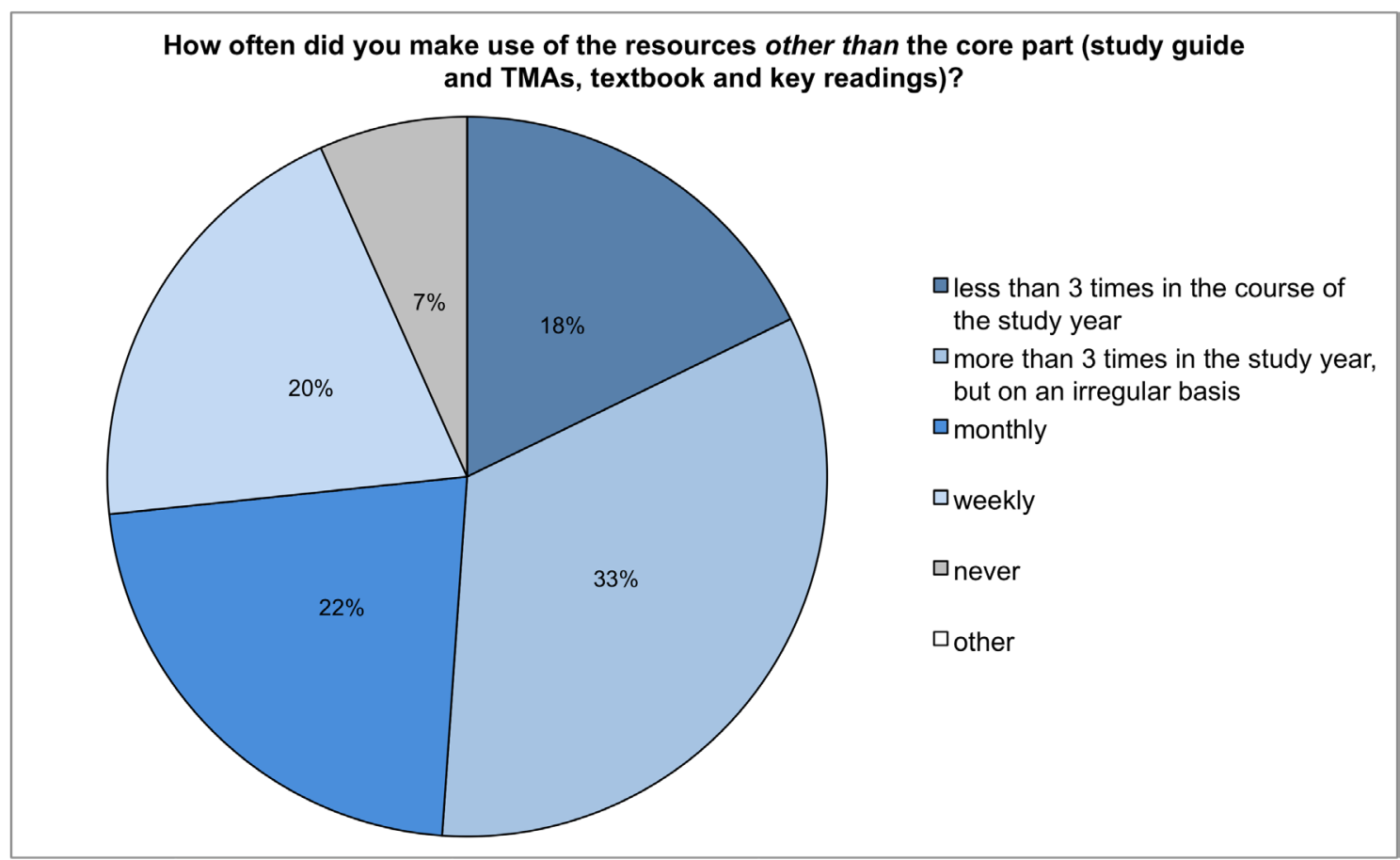

Figure 5. Frequency of student use of extra, non-examinable resources provided. 
Table 1

Resource Use, Average Rank, and Rank Frequency

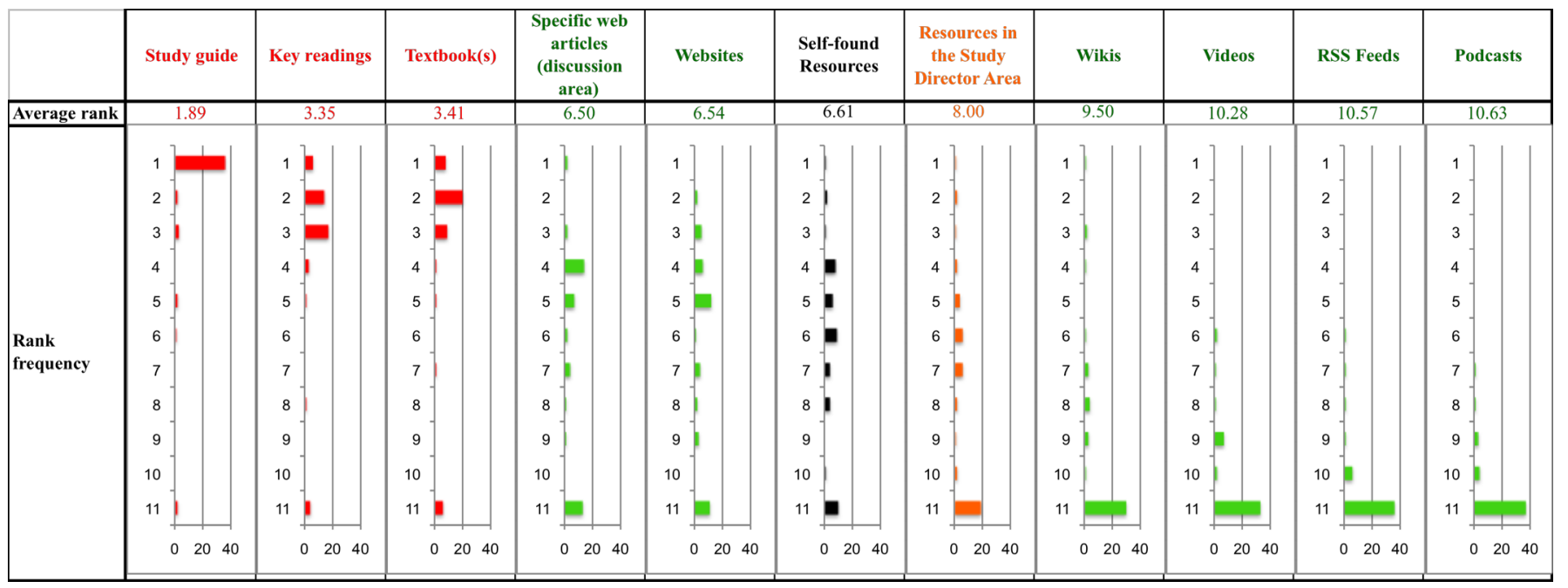


Students reported using the study guide, key readings, and textbook (examinable material) the most, followed by Web sites and self-found resources (i.e., those not pointed out to them by the tutor or found in the course material) (Table 1). The transversal discussion areas (i.e., the non-module-specific Study Director discussion area), wikis, videos, RSS feeds, and podcasts were reported as being used very little (Table 1). The change of online environment did not impact the use of extra resources, with 22 students reporting no change in their use of extra resources. Time (or lack thereof) was outlined explicitly by 13 students as the main constraint for not using extra resources. Work pressures, family situations, and the high number of resources available were specifically mentioned as reasons behind this lack of time. One student working in the field also mentioned a poor Internet connection as a limitation. In the students' comments, extra resources were identified as mostly used to check on a concept or understand it better or as sources of real-life examples to include in tutor-marked assignments.

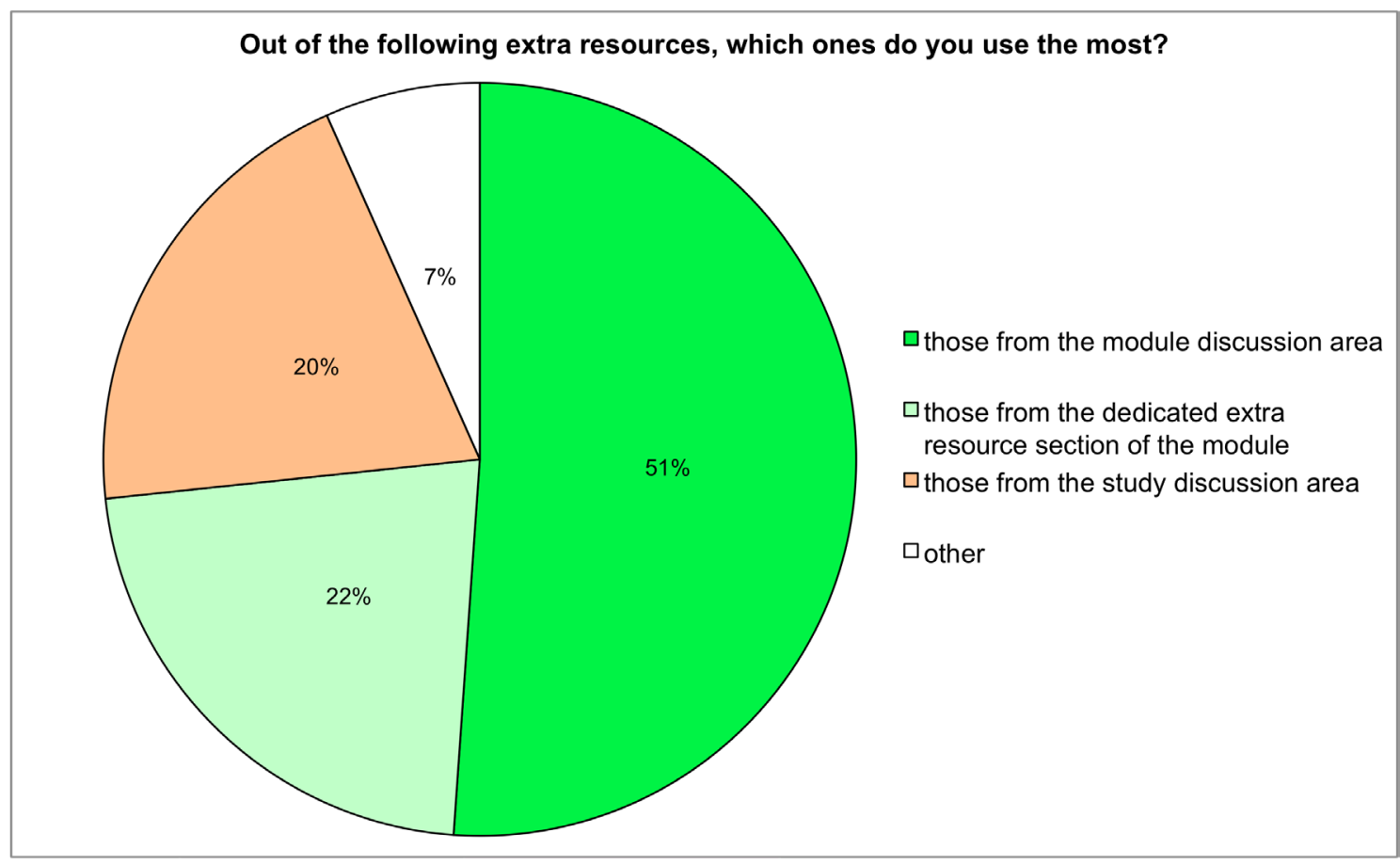

Figure 6. Student use of extra resources depending on their type and location. 


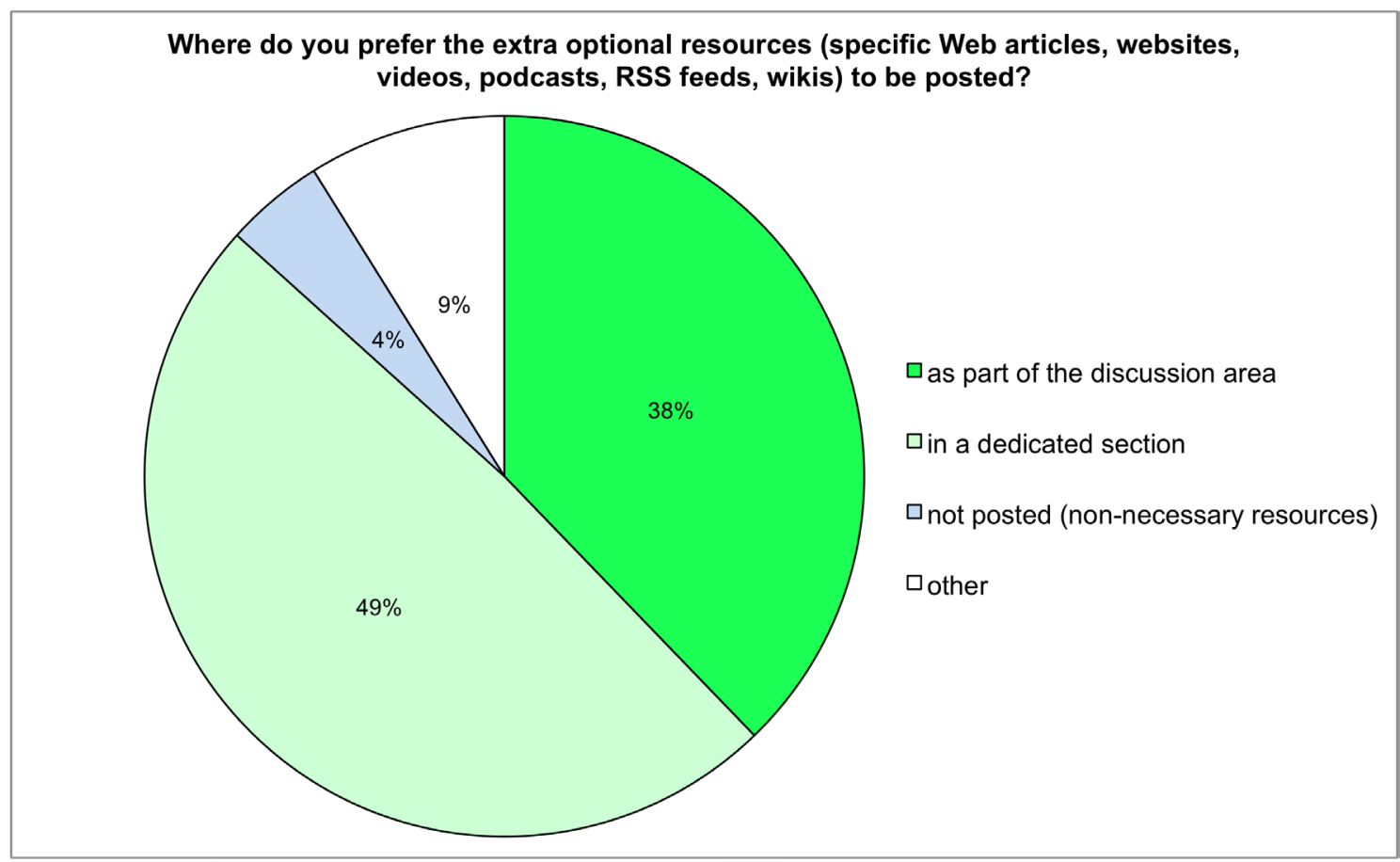

Figure 7. Student preference for extra resource location.

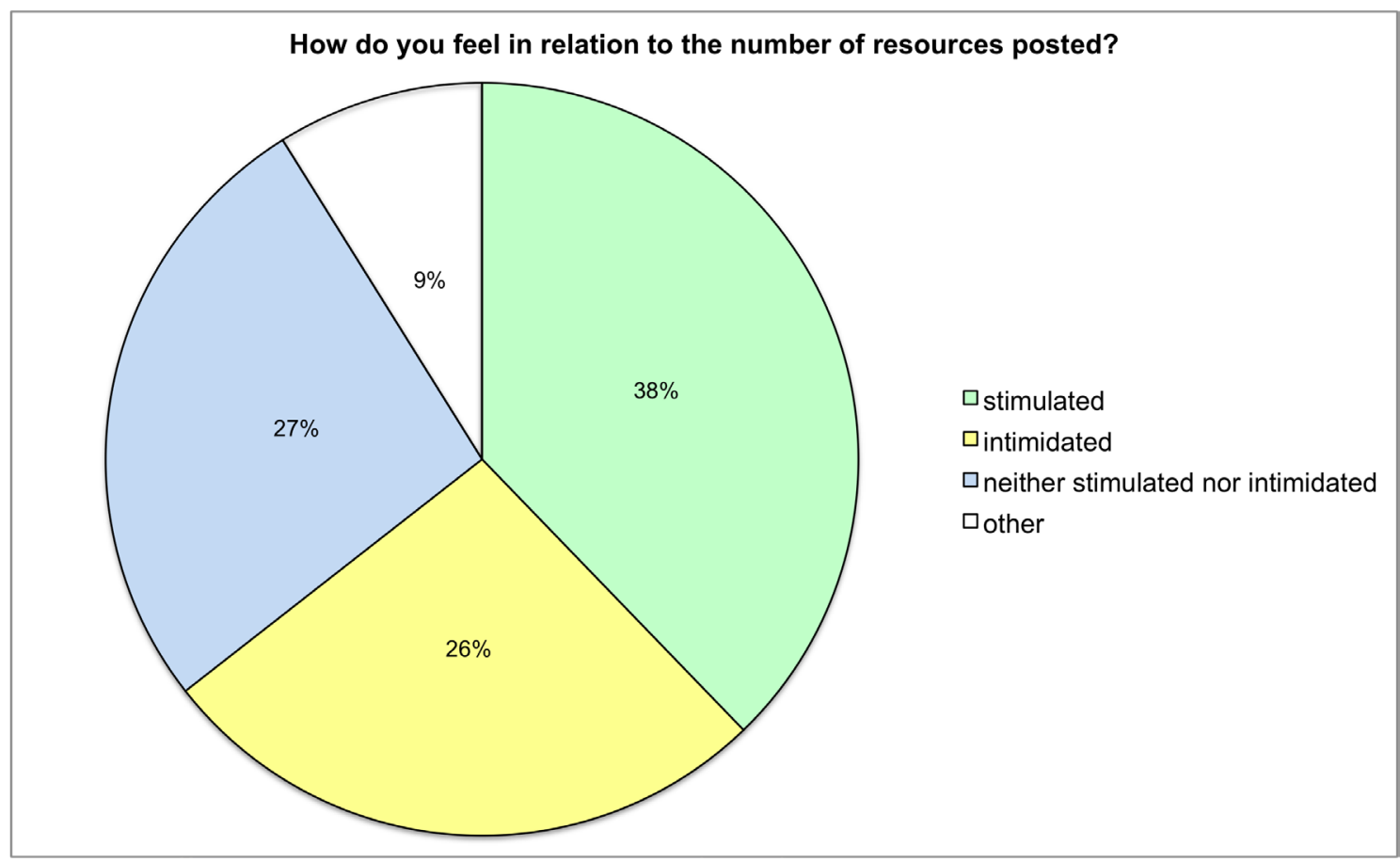

Figure 8. Student feelings about the number of extra resources posted.

Students tend to use extra resources from the module discussion area or e-digests the most (Figure 6) as these resources are more focused, specific, and explicitly linked to the course content. Students seem to prefer extra resources to be posted in separate sections, followed by preferring them to be posted in the discussion area (Figure 7). Students do not wish for more initiative to find extra resources (31 students). In spite of these findings, students 
reported overall that they felt stimulated by the number of resources posted (Figure 8). Students also found it easy to link the material together, with the extra resources sufficiently linked to the rest of the material (23 students). Twenty-nine of the 46 students reported having a native language other than English. Despite this, students overall reported a strong preference for resources in English (28 students), followed by resources in different languages but with English as the main language (15 students). Twenty-four of the 46 students reported using the indicative calendar (paper version or online). A majority of students out of those who answered the question reported using the online calendar less frequently than the paper version ( 9 students). Students also found the online version to be as helpful as the paper one to keep up with the pace of study (16 students). In their comments, students reported using one or the other depending on their personal context, with the online calendar preferred when travelling and the paper version in areas of limited Internet access. Some students also reported not being aware of the existence of the online calendar.

\section{Discussion}

Most students seem to have limited time available for learning because of family and/or child-care responsibilities, and/or because they work outside of normal office hours. Also, about half the respondents were based outside Europe and North America and might therefore face limited technological access (e.g., limited Internet coverage or connection, power cuts) despite most students not explicitly reporting this as an issue. These students thus seem to face a relatively strong time constraint. This seems to be the most limiting factor affecting the amount of material covered.

To answer the first question, students perceive the increased material availability (extra resources) as stimulating, which should improve their learning. Because of the low usage of these resources, there is no clear evidence from this analysis that this increased material availability makes student learning more effective overall (possibly marginally). To answer the second question, students seem to be more concerned about making their learning more time-effective than exploring non-examinable resources associated with specific technologies. To answer the third question, the embedded format of the extra resources has not been associated with any reported change in the use of the virtual learning environment. The embedded format of the extra resources does not in itself appear sufficient for increased learning so far. To answer the fourth question, students tend to focus on resources specifically outlined in the discussion area (still posted as threads) rather than the more general embedded additional resources in a dedicated folder. To answer the fifth question, students preferred the status quo option with no more linkages built into the material and requiring no more initiative.

From these answers, what seems to stand out is that because of the strong time constraint, students do not actually use the (non-examinable) extra resources much, unless these resources are made more time-effective. It would thus seem that adding new resources, each with its specific technological tools, does not necessarily enhance student learning other than by increasing student stimulation to study and learn from the course. This finding 
would underline the idea that time-constrained students do not necessarily find value in the extra resources and technologies used as such, but rather focus on the examinable core material and well-targeted relevant resources. What might seem a very intuitive finding was, however, not necessarily obvious when starting this study. Indeed, distance learning has been advocated in the literature as loosening the time constraint, especially when compared to face-to-face learning (see Blakelock \& Smith, 2006). Replacing face-to-face interaction with distance learning gives more flexibility in the learning space and pace, and distance learning students could endogenously choose this form of learning over face-toface interaction because they are very time-constrained. Distance learning students have more time to focus on the core knowledge acquisition (i.e., the physical representation of what they have paid for) than they do in a face-to-face setting. The students' total time possibly allocated for studying, however, remains limited, with still too little time to fully exploit the extra opportunities afforded them by technological advances. From this study, it is clear that distance learning modules should be designed to allow the online environment to be used less than one hour a week. This usage mostly includes access to non-examinable "green" or "orange" resources as the core material is also distributed to students to allow off-line use (paper or DVD-ROMs).

The sixth question cannot be fully answered in this paper. Students seem to choose to use one form of the calendar or the other (paper or online) based on pragmatic reasons, with a preference for the paper version. A full comparison between the two forms of the calendar is not possible at this stage, however, because of the very limited data on the online calendar use. Because of the lack of awareness about the online calendar in 2009, more systematic publicity has been provided since 2010. The medium has also been changed (to Google Calendar) to make it easier for students to personalise as the calendar can now be easily imported to each student's SOAS Google email account. It is difficult to assess whether more students are using this version of the calendar, however, because it can be imported without any direct involvement by the tutor. Some students are in school all year long while others concentrate their study time during specific periods of the year, and the indicative study calendar might match all students' needs in this context.

Because students make limited use of the extra resources subject to their own initiative, this could undermine the implicit learning objective of fostering independent study (Beaudoin, 1990). Setting initiative and participation as a module outcome might be irrelevant as such here, however. As most students are already working professionals, they do not need to learn these particular skills to prepare them for their professional life and might be more interested in acquiring knowledge instead. Similarly, students should already know how to filter information to find relevant points and do not need to acquire this skill. The provision of targeted resources allowing them to acquire knowledge most time-effectively might then be their own objective. Ascertaining specific students' objectives for taking up these courses would require further investigation, however.

The current course design seems to be implicitly judged by students as sufficiently suited to their needs, making additional resources superfluous. The limited use of non-examinable resources could also be linked to their non-examinability. However, because of the strong 
time constraint students are facing, making non-examinable resources examinable might not increase students' learning and might even have an adverse effect on their motivation to study. It could also increase the number of students deferring their exams to the following year to have more time to cover the increased amount of examinable material. A change in the current toolbox organisation (with the addition of more examinable "red" tools) would thus not necessarily lead to increased learning.

\section{Conclusion}

The push by technologists for the greater use of teaching technologies has clearly helped to extend the teaching toolbox. One associated danger is that it could dilute students' efforts and focus away from the core knowledge or skills to be learned. This could also, for already time-constrained students, reduce the actual study time by increasing the time needed to find or identify relevant information. This paper developed a conceptual framework for information load management to identify the main factors underlying students' use of learning resources. The module has been conceptualised as a toolbox of different teaching and learning resources (each associated with specific technologies). The focus of this analysis has been placed on students' use of the different tools, specifically the non-examinable (optional) material. This led to an assessment of whether the opportunities provided to students-in terms of "extending the toolbox" through the provision of extra resources-were actually taken.

This study has shown that the increased availability of extra resources associated with technological developments has not been sufficient to increase any self-reported use of these extra resources by students. This study has thus highlighted the need to take into account both the supply of resources and technologies as well as students' needs and demands. If not, the danger is that these resources will not be used even on a voluntary basis by students and will therefore not achieve their potential for delivering effective learning.

This study also highlighted that students tend to focus primarily on the examinable material because of the time constraint limiting the amount of material they can cover within a study year. This study strategy would allow distance learning students who are already working full time and who have family duties to maximise their studying and learning timeeffectiveness. This would confirm what the Distance Learning Programme staff members have observed over the years.

This study clearly outlines the need to make the distance teaching toolbox more time-efficient for students to use (i.e., in relation to their needs and not just based on the technology supply). This might be the best strategy to actually enhance learning rather than just extending the toolbox or increasing the core examinable material. Students' time constraints as well as technology accessibility clearly influenced the module design discussed in this paper, with an encouraged but voluntary use of extra resources. The current approach, identifying formally assessed core material to be covered, would seem to help students prioritise their studying efforts, thus potentially making their learning more effective. This might 
be the most suitable approach in this context as it gives students the flexibility to look for information by themselves while providing a good, already quite time-demanding, minimum basis to be covered compulsorily.

The main implication for this study is that universities should focus on providing opportunities for learning to their students but take into account the personal and/or professional constraints faced by those students. The construction of learning toolboxes rather than individual tools could be a way to deliver actual and effective student-centred blended learning. This is especially important as time constraints placed on both distance and faceto-face students are likely to increase. The framework described in this paper could help design and organise module content in relation to the targeted student population. This study also underlines that non-examinable resources provided to students on the online environment should be limited to what can be covered in less than an hour a week.

Further research could look into the virtual learning environment design as a critical factor in making the finding of information and resources more time-efficient. A change in the relative balance of core examinable and optional resources could also be considered for the same amount of material feasibly covered by distance learning students. The core part being quite time-demanding already, reducing it could lead students to use their own initiative and browse extra resources more frequently. This would, however, go back to the debate about what students are actually paying for (i.e., studying material or studying opportunities) and how inclusive (e.g., for students with technologically constrained access) we want the teaching and learning to be.

\section{Acknowledgements}

I am very grateful to the editor and the two anonymous reviewers for their helpful comments on previous versions. I also thank Laurie Smith and Andrew Dorward at SOAS for allowing me to conduct this research and for their very valuable comments on the survey design. I also thank Martin Gough (University of Kent) for his feedback and constructive comments. I would also like to thank all the students who took some of their limited time to answer the survey. 


\section{References}

Anderson, T., \& Garrison, D. R. (1998). Learning in a networked world: New roles and responsibilities. In C. Gibson (Ed.), Distance learners in higher education (pp. 97-112). Madison, WI: Atwood Publishing.

Anderson, T. (2003). Getting the mix right again: An updated and theoretical rationale for interaction. International Review of Research in Open and Distance Learning, $4(2)$.

Arendt, A. M., \& Shelton, B. E. (2009). Incentives and disincentives for the use of OpenCourseWare. International Review of Research in Open and Distance Learning, $10(5)$.

Artino, A. R., Jr. (2009). Online learning: Are subjective perceptions of instructional context related to academic success? Internet and Higher Education, 12, 117-125.

Beaudoin, M. (1990). The instructor's changing role in distance education. The American Journal of Distance Education, 4(2).

Beldarrain, Y. (2006). Distance education trends: Integrating new technologies to foster student interaction and collaboration. Distance Education, 27(2), 139-153.

Berenson, R., Boyles, G., \& Weaver, A. (2008). Emotional intelligence as a predictor for success in online learning. International Review of Research in Open and Distance Learning, 9(2).

Blakelock, J., \& Smith, T. E. (2006). Distance learning: From multiple snapshots, a composite portrait. Computers and Composition, 23, 139-161.

Boitshwarelo, B. (2009). Exploring blended learning for science teacher professional development in an African context. International Review of Research in Open and Distance Learning, 1O(4).

Bose, K. (2003). An e-learning experience: A written analysis based on my experience with primary school teachers in an e-learning pilot project. International Review of Research in Open and Distance Learning, 4(2).

Bouras, C., Destounis, P., Garofalakis, J. D., Gkamas, A., Sakalis, G., Sakkopoulos, E., Tsaknakis, J., \& Tsiatsos, T. (2000). Efficient web-based open and distance learning services. Telematics and Informatics, 17, 213-237.

Bray, E., Kumiko, A., \& Dlugosh, L. (2008). Predictors of learning satisfaction in Japanese online distance learners. International Review of Research in Open and Distance Learning, 9(3).

Brindley, J. E., Walti, C., \& Blaschke, L. M. (2009). Creating effective collaborative learning 
groups in an online environment. International Review of Research in Open and Distance Learning, $10(3)$.

Brown, A. H., \& Green, T. (2009). Time students spend reading threaded discussions in online graduate courses requiring asynchronous participation. International Review of Research in Open and Distance Learning, 10(6).

Calder, J. (2000). Beauty lies in the eye of the beholder. International Review of Research in Open and Distance Learning, 1(1).

Cheaney, J., \& Ingebritsen, T. S. (2005). Problem-based learning in an online course: A case study. International Review of Research in Open and Distance Learning, 6(3).

Debande, O., \& Ottersten, E. K. (2004). Information and communication technologies: A tool empowering and developing the horizon of the learner. Higher Education Management \& Policy, 16(2), 31-61.

Garrison, D. R., \& Kanuka, H. (2004). Blended learning: Uncovering its transformative potential in higher education. Internet and Higher Education, 7, 95-105.

Kirkwood, A., \& Price, L. (2006). Adaptation for a changing environment: Developing learning and teaching with information and communication technologies. International Review of Research in Open and Distance Learning, 7(2).

Kodama, M. (2001). Distance learning using video terminals-an empirical study. International Journal of Information Management, 21, 227-243.

Lynch, R., \& Dembo, M. (2004). The relationship between self-regulation and online learning in a blended learning context. International Review of Research in Open and Distance Learning, 5(2).

Phipps, R., \& Merisotis, J. (1999). What's the difference: A review of the contemporary research on the effectiveness of distance learning in higher education. Journal of Distance Education / Revue de l'Enseignement à Distance, 14(1), 102-114.

Pituch, K. A., \& Lee, Y.-k. (2006). The influence of system characteristics on e-learning use. Computers and Education, 47, 222-244.

SOAS. (n.d.). Why distance learning? Centre for Development, Environment and Policy. Retrieved from http://www.soas.ac.uk/cedep/why/

\section{Athabasca University $\mathbf{C}$}

